\title{
Mature maternity: long term associations in first children born to older mothers in 1970 in the UK
}

\author{
JI Pollock
}

\begin{abstract}
Study objectives - To identify the physical, behavioural, medical, and educational outcomes in first children born to women aged 30 or more compared with those born to younger women.
\end{abstract}

Design - Longitudinal cohort study design employing logistic regression analysis of data obtained from the British births survey of 1970 and the child health and education study follow ups to this cohort at ages 5 and 10.

Setting - One week birth cohort covering the whole of the United Kingdom.

Participants - The carers of 4315 first children born to women during the week of April 5th-11th 1970 inclusive in the whole of the United Kingdom except Northern Ireland, and followed up at both 5 and 10 years of age. In addition, information was obtained from health visitors, the child's teacher at 10 , and the medical officer who completed an examination. At 10 the child also completed a questionnaire.

Measurements - Data were obtained from questionnaires administered to the carers of the child at each time point, from their teacher at age 10, and from the results of a medical examination at age 10 . Educational tests were also conducted at this age.

Main results - Having adjusted for the effects of confounding factors, late primiparity was significantly associated with a number of events in labour and delivery involving obstetric interventions ranging from induction to operative deliveries and general anaesthesia. At 5 years of age, controlling additionally for family size at that time, associations were found between late primiparity and fewer adverse measures of behaviour in the child. Both the child's head circumference and the score on a picture based vocabulary test at this age were slightly greater in the index group. At 10 years of age, adjusting for background factors and present family size, late primiparity was associated with few outcome measures. Children born to older mothers, however, scored slightly higher on a broad range of educational tests administered at school.

Conclusions - No clearly demonstrable adverse outcomes could be linked to later primiparity in the 1970 child health and education study national cohort study. Modest behavioural and educational advantages were detected in the group with older first-time mothers. A woman's later primiparity may be associated with their child having a slightly larger head circumference compared with whole of the rest of the study cohort.

$(\mathcal{F}$ Epidemiol Community Health 1996;50:429-435)

Although the mean age at which women have their first baby has not changed dramatically in recent times, appreciable secular trends are evident in the fertility of different age groups. Maternal age data were first systematically collected by the Office of Population Censuses and Surveys (OPCS) in 1938 and subsequent statistics show that following the post war baby boom, which affected all age groups, there has been an overall decline in the fertility of women in the 30-34 and 35-39 age groups (fig 1). The trend was particularly strong from the middle to late 1960 s when effective contraception allowed women to plan their families better. It is often thought that the prime impact of this technology was to control pregnancies in the youngest age groups, but the population data also show large reductions in women from the older age brackets who were able to limit the size of their families.

The nadir of fertility in the older age groups in the UK was reached in the late 1970s and during the last 10 years the fertility rate for women in their 30 s has increased by about $30 \%$, perhaps partly as older women rejected the contraceptive pill as much as a planned shift in reproductive strategy. In the USA the fertility rate of women in the 30-34 and 35-39 age brackets quadrupled between 1970 and 1986.

There have also been substantial secular increases in the proportion of (legitimate) first births occurring to older women (fig 2). The overall trend is largely unaffected by significant reductions in birth rate in younger age groups and is much more marked in the $30-34$ year old age band. In the UK the OPCS provide incomplete statistics on maternal age and birth order as births of specified order to unmarried women are not collated by maternal age. However, for all births outside marriage there is a marked shift towards the older age groups (fig 3).

Shorter childbearing 'windows' make today's ideally planned family more uncertain for mature mothers with developed careers. There are no population based data on the prevalence of older 'intending mothers' who do not have babies but studies of 'natural' human populations show an almost linear loss of fertility from the mid-20s. ${ }^{2}$ A recent study from an artificial 


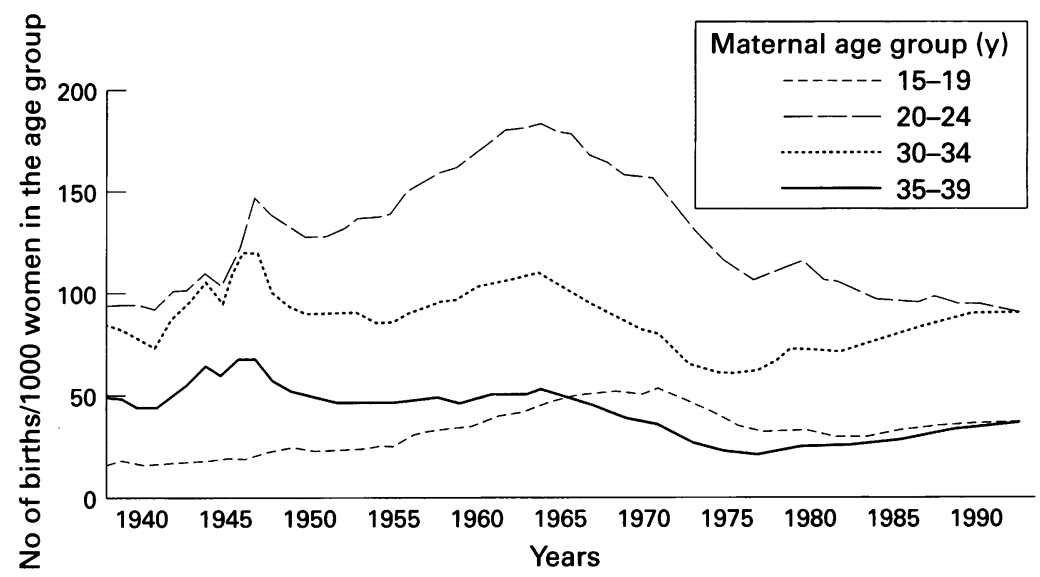

Figure 1 Age specific maternity rates in the study population. Number of live births per 1000 women in the age group (England and Wales)

insemination clinic indicates that by the age of 35 the ability of a woman to conceive (female fecundity) is one half of the value at age $25 .^{3}$

Once pregnancy is achieved reported maternal age related complications include multiparity, chromosomal abnormalities, miscarriage, late fetal death, and maternal mortality. ${ }^{2}$ Complications of pregnancy such as diabetes, hypertension, and haemorrhage, ${ }^{4}$ prolonged labour, ${ }^{5}$ and preterm delivery ${ }^{67}$ have all been cited as difficulties facing the older primipara. The neonate may have a lower birth weight, ${ }^{8}$ and consequently a higher mortality and morbidity,

Many studies, however, by including inappropriate or insufficient control for important confounding factors have been methodologically or statistically flawed. ${ }^{9}$ The influences of age and parity, for example, are rarely disentangled. First babies born to older women have a higher neonatal mortality, although the overall risk of a neonatal death to older women is little changed. One difficulty of research in this area lies in the need to separate those women who delay childbearing intentionally from those in whom it is involuntary. Thus, when adjustments were made for the higher prevalence of previous miscarriage or infertility in women of at least 30 years of age having their first baby, no increased risk of low birth weight or preterm delivery were found, and mean birth weight and gestational age at delivery were normal. ${ }^{10}$ There was, however, a statistically non-significant but suspiciously high risk

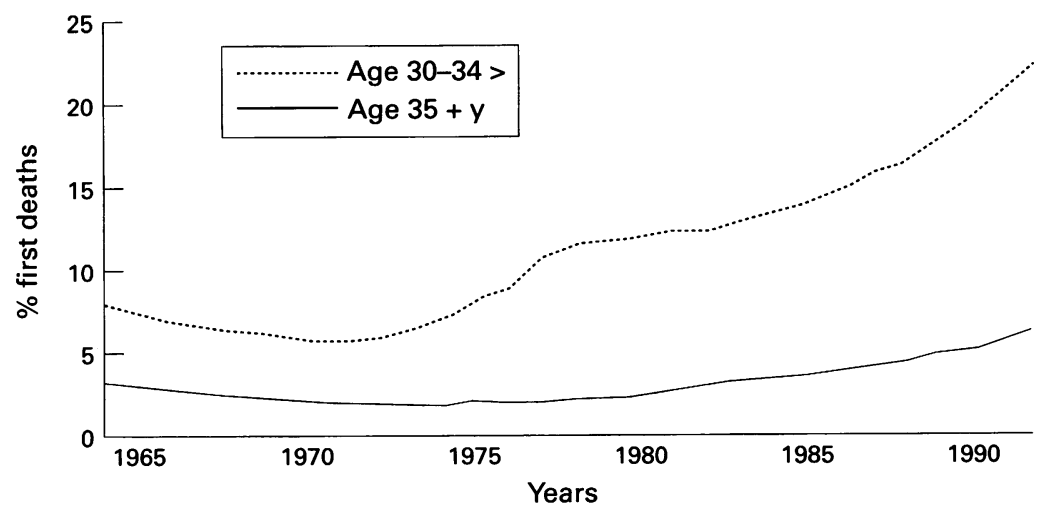

Figure 2 Trends in first births to older women. (UK data from England and Wales, legitimate live births only.) of preterm birth in the group aged 35 years and more in this study and in one conducted on a similarly aged British population that was also controlled for measures of infertility. ${ }^{11}$ Recent work with rather more careful statistical analysis indicates that older first time mothers are at increased risk of pregnancy complications, preterm delivery, and having babies of low birth weight, ${ }^{12}{ }^{13}$ although others place these risks firmly in the 'manageable' category. ${ }^{14}$

For these reasons and because of studies conducted in the past when maternal nutrition and health were considered poorer, ${ }^{15}$ there has been a reasonable tendency for obstetricians to be cautious about managing first pregnancies in the older age groups. This in itself is likely to increase the detection and 'solution' of obstetric complications and increase operative delivery rates both iatrogenically and to 'protect' especially precious infants. ${ }^{11}$

While the conclusion that can be drawn from published research indicates that first births to mothers aged up to 35 are generally at comparatively low risk of immediate adverse outcome, very little is known about the consequences for the child in the longer term. Circumstances differ for these children in ways which might be both beneficial and disadvantageous. ${ }^{16}$ The first child born to the older mother may be more likely to have no younger siblings and to be cared for by adults other than their parents; they may also receive extra care and attention as a much wanted child and experience greater protectiveness. They may live in economically advantaged conditions with material benefits and have professionally experienced parents. ${ }^{17}$ They, and their parents, are less likely to receive care and attention from ageing grandparents. One picture painted of the increasingly prevalent elderly primipara in the United States is of a well educated, well nourished woman engaging in positive health behaviour with optimal antenatal care. ${ }^{18}$

These children have not, however, been systematically followed up. To rectify this situation partially, an epidemiological analysis was conducted on the British births survey cohort of children, with its subsequent 5 and 10 year follow ups, in order to see if later primiparity could be linked, on a population wide basis, firstly to complications of pregnancy and management of labour and delivery, and then to medical, behavioural and intellectual characteristics of the child at 5 and 10 years of age.

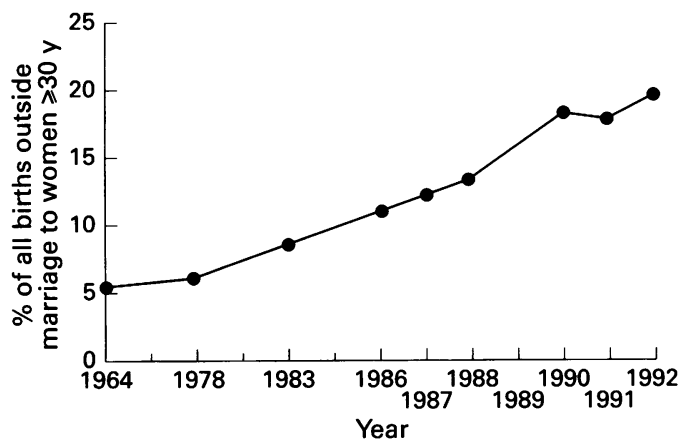

Figure 3 Births outside marriage (England and Wales). 


\section{Methods}

STUDY SAMPLE

The British births survey (BBS) of 1970 was undertaken in order to repeat and contemporise the success of an earlier birth survey (British perinatal mortality survey) in providing information to improve maternal and neonatal care services. An estimated $98 \%$ of the births occurring in the week 5-11 April 1970 throughout the UK were monitored. ${ }^{19}$ For each birth a questionnaire was completed by the midwife covering aspects of the social, medical and biological background of the mother and family, as well as details of the pregnancy, labour, and early postnatal period (up to 7 days post partum)

This cohort, which originally numbered 17196 children, was again traced at 5 years of age by the criterion of birth date via the NHS central register and the GPs to whom each child was attached. Northern Ireland was excluded from the follow up survey for reasons of political sensitivity, and the number of children actually traced was further amended by deaths, emigrations, and immigrations in the intervening period. Of the 13961 children traced (approximately $86 \%$ of the surviving BBS cohort), 13135 completed questionnaires, with the aid of the health visitor network.

In $1980,94 \%$ of the birth cohort survivors were again traced through educational registers and a battery of tests and questionnaires together with a medical examination were administered in what had become the child health and education survey (CHES).

For the present study, all mothers having their first birth ( $>24$ weeks gestation), and for whom there was information on the child at both 5 and 10 years of age were selected. From these, all women who delivered in Northern Ireland or abroad and those whose age at delivery was unknown were excluded. The total number of women was 4315 , of which $354(8 \%)$ were aged 30 years or older and 3961 were aged less than 30 years.

Factors independently predictive of loss to follow up at either 5 and/or 10 years were region of birth of parents and child, lack of paternal support, being unmarried at the birth of the index child, having used no contraception before the index child pregnancy, attending late for antenatal care and not attending antenatal classes, and heavy smoking. As a

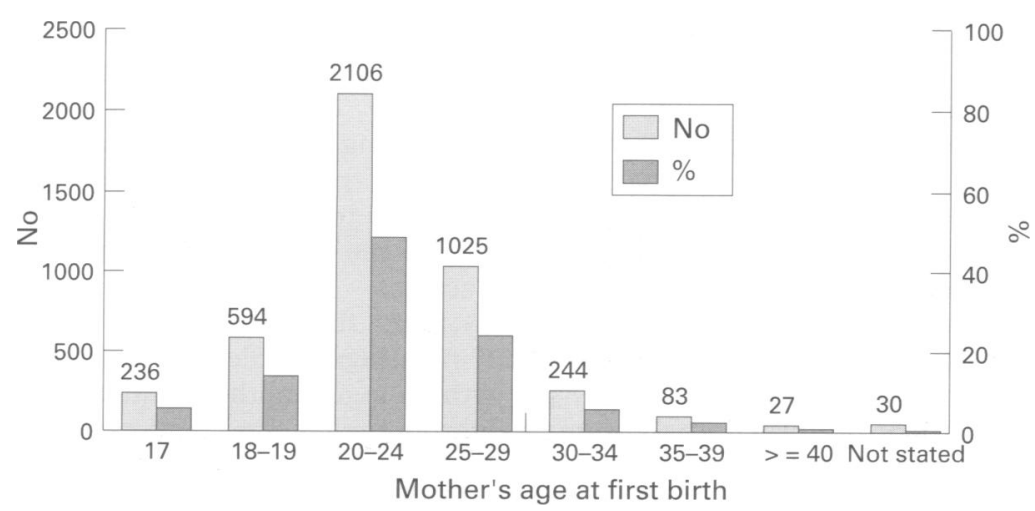

Figure 4 Age distribution of first births (British birth survey, 1970). nationally representative study, the longitudinal cohort described in the analyses below is therefore diminished by a group of families with these specific characteristics of social and economic disadvantage.

\section{METHODS}

Twenty three factors from the BBS describing the mother's background were cross tabulated against dichotomised maternal age group $(<30$ and $30+$ ) and those factors significantly associated by $\chi^{2}$ test $(p<0.05)$ chosen for further consideration. These factors were placed in three groups which described the mothers' social circumstances (for example, marital status, crowding, number of children in household, regional variables, $\mathrm{n}=7$ ), her reproductive history (previous pregnancies and abortions, reproductive intervals, $\mathrm{n}=8$ ), and her personal characteristics (place of birth, occupational class, education, height, smoking, first antenatal appointment date, $\mathrm{n}=8$ ). Factors relating to the age at which the mother or the father left full time education were omitted because of changes in school leaving age policy at this time, being replaced by a factor defining the highest educational qualifications obtained by 1975 . Within each factor those levels which showed similar associations with maternal age, and were logically related to each other were combined in order to minimise the number of similar categories with small numbers.

In each of the three groups, significant variables were entered into a stepwise logistic regression analysis, with age at delivery $(<30 /$ $30+$ years) as the dichotomised dependent variable and a criterion for entry set at $p<0.01$. Those factors from each of the three groups remaining significantly and independently associated with age at delivery were then combined and a final model created. First order interactions were tested for significance $(p<0.05)$, but none were found. These factors were then held constant as associations between late primiparity and characteristics of pregnancy and birth, and the health, behaviour, and development of the child at 5 and 10 years were examined by logistic regression. The number of children born to these families since the index child's birth was included as an additional dependent variable in order to control for family size. Only two tailed tests were employed and in view of the number of tests performed a stringent significance level criterion of $\mathrm{p}<0.01$ was adopted.

\section{Results}

PREDICTORS OF OLDER PRIMIPARITY IN 1970

The maternal age distribution of first time births in this cohort indicates (fig 4) that in 1970 only $8 \%$ of those having their first baby were aged 30 or more, with $2.5 \%$ in the $35+$ age band. These data closely agree with OPCS statistics, which cover legitimate live births only (fig 2) and reflect the nadir of the trend that has since manifested itself.

The older age group were more likely to deliver in north Wales or in the south-east, to have no educational qualifications (or voca- 
Table 1 Final model of factors independently predicting mature primiparity

\begin{tabular}{|c|c|c|c|}
\hline & $\begin{array}{l}\text { Adjusted odds } \\
\text { ratio }\end{array}$ & $95 \% C I$ & $x^{2} p$ \\
\hline \multicolumn{4}{|l|}{ Region of delivery: } \\
\hline \multicolumn{4}{|l|}{ North, North-West, Yorks and } \\
\hline Humberside & 0.82 & $0.62,1.08$ & \multirow{9}{*}{$\begin{array}{l}23.24^{\star \star} \\
{[8 \mathrm{df}]}\end{array}$} \\
\hline Scotland & 0.80 & $0.49,1.31$ & \\
\hline East Midlands & 0.57 & $0.32,0.99^{\star}$ & \\
\hline West Midlands & 1.19 & $0.84,1.67$ & \\
\hline East Anglia & 0.83 & $0.45,1.54$ & \\
\hline South West & 0.97 & $0.62,1.53$ & \\
\hline South Wales & 0.87 & $0.48,1.59$ & \\
\hline North Wales & 2.28 & $1.30,4.02^{\star}$ & \\
\hline South-east, London & 1.40 & $1.09,1.80^{\star}$ & \\
\hline \multicolumn{4}{|c|}{ Highest educational qualification of either parent by 1975 : } \\
\hline None, vocational & 1.37 & $1.14,1.65^{\star}$ & \multirow{3}{*}{$\begin{array}{l}16.79^{\star \star \star} \\
{[2 \mathrm{df}]}\end{array}$} \\
\hline ' $\mathrm{O}$ ' level or equivalent & 0.66 & $0.53,0.83^{\star}$ & \\
\hline 'A' levels or equivalent, higher degree & 1.10 & $0.90,1.34$ & \\
\hline \multicolumn{4}{|l|}{ Mother's occupational class in 1970: } \\
\hline SC I, II & 1.58 & $1.2,1.94^{\star}$ & \multirow{3}{*}{$\begin{array}{l}21.95^{\star \star \star} \\
{[2 \mathrm{df}]}\end{array}$} \\
\hline SC III (NM and $M$ ) & 0.76 & $0.64,0.90^{\star}$ & \\
\hline SC IV, V & 0.83 & $0.66,1.04$ & \\
\hline \multicolumn{4}{|l|}{ Marital status at conception: } \\
\hline Married & 2.79 & $2.22,3.51^{\star}$ & \multirow{2}{*}{$\begin{array}{l}117.97^{\star \star \star} \\
{[1 \mathrm{df}]}\end{array}$} \\
\hline Unmarried & 0.36 & $0.28,0.45^{\star}$ & \\
\hline \multicolumn{4}{|l|}{ No of people per room in house [at age } \\
\hline 5]: & & & \multirow{5}{*}{$\begin{array}{l}95.22^{\star \star \star} \\
{[3 \mathrm{df}]}\end{array}$} \\
\hline$\leqslant 0.5$ & 2.59 & $1.83,3.66^{\star}$ & \\
\hline $0.5-0.75$ & 1.73 & $1.39,2.14^{\star}$ & \\
\hline $0.75-1.0$ & 0.58 & $0.47,0.71^{\star}$ & \\
\hline$>1.0$ & 0.39 & $0.28,0.53^{\star}$ & \\
\hline \multicolumn{4}{|l|}{$\begin{array}{l}\text { No of older children in household in } \\
1975\end{array}$} \\
\hline None & 0.59 & $0.46,0.76^{\star}$ & \multirow{2}{*}{$\begin{array}{l}13.74^{\star \star \star} \\
{[1 \mathrm{df}]}\end{array}$} \\
\hline Any & 1.69 & $1.31,2.18^{\star}$ & \\
\hline \multicolumn{4}{|l|}{$\begin{array}{l}\text { Contraception used in previous } 18 \\
\text { months: }\end{array}$} \\
\hline None & 1.87 & $1.55,2.24^{\star}$ & \multirow{3}{*}{$\begin{array}{l}52.66^{\star \star \star} \\
{[2 \mathrm{df}]}\end{array}$} \\
\hline Pill & 0.52 & $0.41,0.67^{\star}$ & \\
\hline Other & 1.02 & $0.83,1.26)$ & \\
\hline
\end{tabular}

* Categories with adjusted odds ratios significantly $(\mathrm{p}<0.05)$ deviant from 1 .

${ }^{\star \star} \mathrm{p}<0.01 .^{\star \star \star} \mathrm{p}<0.001$.

Table 2 Adjusted ${ }^{\star}$ associations between mature primiparity and obstetric factors (only associations with $p<0.01$ listed)

\begin{tabular}{lll}
\hline & Adjusted odds ratio $(95 \%$ CI $)$ & $\chi^{2}{ }_{1 d f^{p}}$ \\
\hline Antenatal care: & & \\
$\quad$ Hospital responsible & $3.20(2.23,4.58)$ & $50.24^{\star \star \star}$ \\
$\quad$ GP responsible & $0.65(0.49,0.85)$ & $8.98^{\star \star}$ \\
Place of delivery: & $0.53(0.34,0.82)$ & $8.95^{\star \star}$ \\
$\quad$ At place of booking for delivery & $2.40(1.69,3.41)$ & $28.15^{\star \star \star}$ \\
$\quad \begin{array}{l}\text { Delivery in consultant bed } \\
\text { Delivery at home }\end{array}$ & $0.16(0.04,0.69)$ & $10.93^{\star \star \star}$ \\
Labour: & $1.79(1.39,2.30)$ & $20.15^{\star \star \star}$ \\
$\quad$ Induced & $2.63(1.85,3.74)$ & $26.3^{\star \star \star}$ \\
$\quad$ General anaesthetic & $2.56(1.99,3.28)$ & $53.77^{\star \star \star}$ \\
Method of delivery: & $1.85(1.41,2.41)$ & $19.51^{\star \star \star}$ \\
$\quad$ Not spontaneous & $3.22(2.17,4.77)$ & $30.58^{\star \star \star}$ \\
$\quad$ Forceps, vaccuum extraction & & \\
$\quad$ Caesarean section & $1.45(1.12,1.89)$ & $7.64^{\star \star}$ \\
Postnatal: & Separation of mother from baby $\geqslant 24 \mathrm{~h}$ & \\
\hline
\end{tabular}

* Adjusted for: region of delivery, highest educational qualifications of parents, mother's occupational class, marital status at conception, number of people per room in household, number of older children in household (1975), and contraception used in previous 18 months. ${ }^{\star \star} \mathrm{p}<0.01 .^{\star \star \star} \mathrm{p}<0.001$
ADJUSTED ASSOCIATIONS WITH OLDER

PRIMIPARITY

Pregnancy and birth

A total of 42 dichotomised factors defining the gestation, labour, delivery, and early post partum period were examined for significant $(\mathrm{p}<0.01)$ associations with older age at delivery, having adjusted for background variables as previously determined (table 2). The probability of at least one result being significantly associated by chance was 0.4 .

A total of 11 associations were found to meet the significance criterion. Later primiparity was associated significantly with the hospital (and not the GP) being responsible for antenatal care and for delivery in a consultant bed (but not at home). Delivery was less likely to have occurred at the place of booking and labour was more likely to be induced. Delivery was less likely to be spontaneous, with operative procedures and general anaesthetics being more widely employed. The mother and baby were more likely to be separated after birth for at least 24 hours.

Despite these differences in obstetric practice there were no other indications of pregnancy complications or a poorer infant condition prenatally or postnatally in the study cohort. On a population basis there were no differences in rates of hypertension, maternal haemoglobin, antepartum haemorrhage, fetal heart rate abnormalities, or birth weight. There were similarly no differences between the maternal age groups, after adjustment, in the infant's time to breathe or requirement for rescusitation, or breast feeding in the post partum period.

There was a slight indication of lower gestational ages at delivery but the standard errors were high and it is impossible to exclude clinical intervention as a major confounding factor.

Characteristics of the 5 year old child born to older mothers

At 5 years of age the number of younger children in the household was added as an additional independent variable so that confounding by family size and additional children could be avoided. The following results are therefore further adjusted for this factor.

Only 7 out of 74 associations ( 0.7 expected by chance) met the significance criterion at 5 years, and 6 were closely interrelated (table 3 ). The 5 year old children of mature primiparae were less likely to have been reported by their mother as being very restless, fighting frequently with other children, being often disobedient and telling lies, and consequently (because they were partly based on these items) were less likely to be in the highest scoring $50 \%$ or $75 \%$ of the population on the Rutter behaviour scale.

Interestingly, the first children of older mothers had indistinguishable health indices from those with younger mothers and were of the same height as their peers. However, they had significantly larger head circumference measures at this age. Furthermore, although their human figure drawing scores and copying 
Table 3 Adjusted ${ }^{\star}$ associations between mature primiparity and characteristics of the child at 5 years of age (only those associations significant at $p<0.01$ listed)

\begin{tabular}{llc}
\hline & Adjusted odds ratio $(95 \%$ CI) & ${ }^{{ }^{2}}{ }_{1 d f}{ }^{p}$ \\
\hline Behaviour (mother's report): & & \\
$\quad$ Very restless & $0.53(0.41,0.69)$ & $21.48^{\star \star \star}$ \\
Fights frequently with other children & $0.61(0.46,0.82)$ & $11.64^{\star \star \star}$ \\
Often disobedient & $0.60(0.46,0.78)$ & $14.15^{\star \star \star}$ \\
$\quad$ Often tells lies & $0.61(0.45,0.83)$ & $10.66^{\star \star \star}$ \\
Rutter scores (based on mother's report): & $0.67(0.50,0.88)$ & $7.69^{\star \star}$ \\
$\quad \geqslant$ lowest $25 \%$ & $0.63(0.49,0.82)$ & $12.36^{\star \star \star}$ \\
$\quad$ lowest $50 \%$ & & \\
Health: & & \\
$\quad$ None & $1.52(1.17,1.97)$ & $10.30^{\star \star}$ \\
Development: & & \\
Head circumference $>51 \mathrm{~cm}$ &
\end{tabular}

^ Adjusted for: region of delivery, highest educational qualifications of parents, mother's

occupational class, marital status at conception, number of people per room in household,

number of older children in household (1975), contraception used in previous 18 months, and

number of younger children in household in 1975.

${ }^{\star \star} \mathrm{p}<0.01 .^{\star \star \star} \mathrm{p}<0.001$

Table 4 Adjusted ${ }^{*}$ associations between mature primiparity and characteristics of the child at 10 years of age (only associations significant at $p<0.01$ are listed)

\begin{tabular}{|c|c|c|}
\hline & $\begin{array}{l}\text { Adjusted odds ratio } \\
(95 \% \mathrm{CI})\end{array}$ & $\chi_{1 d f}^{p}$ \\
\hline \multicolumn{3}{|l|}{ Behaviour (mother's report): } \\
\hline Noticeably clumsy & $0.35(0.15$, to 0.83$)$ & $7.52^{\star \star}$ \\
\hline Likes company & $1.56(1.14,2.14)$ & $8.21^{\star \star}$ \\
\hline Antisocial Rutter score & $0.69(0.53,0.90)$ & $7.36^{\star \star}$ \\
\hline Often goes to museum & $1.54(1.15,2.06)$ & $8.85^{\star \star}$ \\
\hline \multicolumn{3}{|l|}{ Health: } \\
\hline \\
\hline \multicolumn{3}{|l|}{$\begin{array}{l}\text { Physical characteristics and development: } \\
\text { None }\end{array}$} \\
\hline \multicolumn{3}{|l|}{ Intellectual achievements: } \\
\hline Pictorial language comprehension score $\geqslant$ lowest $25 \%$ & $1.86(1.14$, to 3.04$)$ & $6.9^{\star \star}$ \\
\hline Maths test score $\geqslant$ lowest $75 \%$ & $1.67(1.23,2.28)$ & $10.64^{\star \star}$ \\
\hline \multicolumn{3}{|l|}{ British ability scale scores: } \\
\hline Similarities score $\geqslant$ lowest $50 \%$ & $1.67(1.22,2.29)$ & $10.97^{\star \star \star}$ \\
\hline Similarities score $\geqslant$ lowest $75 \%$ & $1.54(1.13,2.08)$ & $7.82^{\star \star}$ \\
\hline Total score $\geqslant$ lowest $75 \%$ & $1.82(1.33,2.50)$ & $14.19^{\star \star \star}$ \\
\hline
\end{tabular}

* Adjusted for: region of delivery, highest educational qualifications of parents, mother's

occupational class, marital status at conception, number of people per room in household,

number of older children in household (1975), contraception used in previous 18 months, and number of younger children in household in 1980

${ }^{\star \star} \mathrm{p}<0.01 .^{\star \star \star} \mathrm{p}<0.001$
However, the index children fared better than their peers in most of the intellectual testing conducted in the school at this time, some of the differences reaching statistical significance. First children with older mothers were more likely to score higher than the bottom $25 \%$ of the cohort in the language comprehension test, higher than the bottom $50 \%$ in the British ability scale similarities test, and to score in the highest $25 \%$ in the maths test, and in both the BAS similarities and overall total score. In 8 of the 9 separate educational tests administered at this time the index children were significantly superior or had appreciably higher adjusted odds ratios for higher scores. Only in the spelling test was there no indication of any difference between the two groups.

\section{Discussion}

Factors predictive of later primiparity in this cohort include those typical of an advantaged group that is probably more strikingly observed today (for example, higher socioeconomic class, married status, living in less crowded conditions). The significantly higher adjusted odds of the group having 'vocational or no educational qualifications' resulted, at least in part, from the poorer educational opportunities and expectations of some of the oldest mothers in the index group, who were of secondary school age during and shortly after the second world war. Lack of contraception also probably reflects both these mothers' age and their desire for children. The association with older children in the household presumably results from marriages into families with existing children as there was a strong link between married status and older primiparity. Straightforward explanations are not available for the association with north Wales and the south-east as regions for delivery, a proxy for their area of residence.

Although a large number of statistical tests were undertaken $(n=270)$ with the prospect of significant events being determined by chance (expected number $=2.7$ ), patterns of association among the 27 significant results may be legitimately discussed. For birth outcomes, the results presented here on a population basis are consistent with differences in obstetric management being unrelated to any measurable differential risk for the child. This does not mean that in any specific individual case obstetric management was unnecessary but it suggests that overall higher rates of obstetric intervention were probably unjustified. However, the study cohort omitted infant deaths. Numbers are too small to identify strong trends, but the relative risk of a pregnancy termination between 24 and 28 weeks in the older age group ( $n=4$ cases) was $4.95(95 \% \mathrm{CI}$ $2.30,10.62$, Fisher's exact test $\mathrm{p}=0.0061)$. Furthermore, many obstetricians would argue that preventive measures reduced the risks of pregnancy in older first time mothers; while this can not be denied for individual situations the present data do not support a higher risk in these cases taken as a whole. It should also be noted that the older age group used in this 
analysis was dominated by women closer to 30 years than to 35 years of age. Risks may be different for the $35+$ age group.

The first babies born to an older mother were unexceptional from the medical perspective and showed no health history differences at 5 years of age. They had slightly larger heads and fewer disruptive behaviours at this age. At 10 there were no physical or health differences, although the larger head circumferences of children of older first time mothers approached significance at the 0.01 level (adjusted odds of head circumferences in the older mother's group greater than the mean for the study cohort $=1.2, \quad 99 \%$ CI $0.98,1.47$, $\mathrm{p}=0.0167$ ). Elements of the 5 year behavioural profile remained at 10 , and educational tests conducted at this age demonstrated a pattern of higher scores in the index group throughout the range of tests, and most markedly in the mathematics and BAS similarities tests. Unlike other cognitive tests spelling performance was not higher in the index group.

Unpublished analyses of the British births survey cohort indicate that the child's head circumference at 5 is a strong predictor of the British ability scale total score at 10 when adjusted for 14 other social, educational, and health factors. The adjusted odds ratio of obtaining a score within the cohort's lowest $25 \%$ on this measure ranged from 1.47 (95\% CI $1.22,1.77$ ) for children with a head circumference less than $50 \mathrm{~cm}$ to $0.8(95 \% \mathrm{CI}$ $0.68,0.95)$ for those greater than $53 \mathrm{~cm}$ $\left(\chi^{2}, 4 \mathrm{df},=35.04, \mathrm{p}<0.0001\right)$.

Similar results were obtained in analyses of both mathematics and reading ability. The few other studies on normal, healthy children have indicated in at least two cases significant positive relationships between head circumference and IQ, cognitive abilities, or educational achievement, ${ }^{20}$ and in at least one, no measurable effects. ${ }^{22}$

Relationships between physical stature and cognitive abilities or achievements have been discussed since the earliest days of anthropology and medicine. A useful review by Rutter $e t$ $a l^{3}$ concluded that shorter height and intellectual retardation were probably related, perhaps mediated through disease, poor nutrition, or biochemical growth parameters. It is unlikely that the present result was confounded by a possible relationship between head circumference and height as no height differences were detected between the groups.

The other results remain of interest and should be confirmed preferably by prospective study. Examination of family circumstances at 10 showed that although the two age groups did not differ in maternal employment or type of mother figure, the children in the younger maternal group were significantly more likely to be living in a home without their natural father. Parental difficulties might have contributed to the educational achievement differences and consequently the 10 year educational outcomes were repeated, adjusting additionally for this factor. The effects of this further adjustment, however, were insignificant.
One might hypothesise that maturity in the mother is associated with better care which filters through into the child's educational abilities. Professionally experienced first time mothers exercising control over their reproductive lives and their career may bring to the family special qualities and parenting styles, including perhaps greater involvement of other adult carers. However, these mothers did not engage in more positive health behaviours. Details of parenting style were not available to the study. Whatever possible benefits older primiparity might bring to the young child later effects may be different. The greater 'maturity gap' between the adolescent born to the older mother, and the parents, the fewer younger siblings, the impact of the mother returning sooner to her career, the earlier experience of bereavement over dying grandparents, may have unknown detrimental consequences in later life.

It is probable that the characteristics of the women who start their families at a later age have changed substantially over the last 25 years. In the USA in 1970 one quarter of primiparae over 30 years old had college degrees. By 1986 it was one half. This means, were a similar pattern repeated here, that outcomes today would probably be more marked in the educational arena than those presented for the cohort born in 1970. Other differences in maternal employment and career progression also make it unwise to extrapolate to the present day. It remains of interest, however, that in a cohort where these factors were of less importance, small advantages remain visible in the children of the older age group of mothers, adjusted for potential confounders. While there are a multiplicity of other factors involved, it seems reasonable to conclude that the known dangers of very early reproduction far exceed those of modestly mature primiparity in obstetric, infant, and child health and in the child's development. The present study was, however, of insufficient power to draw any conclusions about primiparity beyond 40 years of age.

I am pleased to acknowledge the support and advice of Professor J Golding. This work was supported by a grant from The Wellcome Trust. The British births survey was sponsored jointly by the National Birthday Trust Fund and the Royal College of Wy the National Birthday Trust Fund and the Royal College of Obstetricians and Gynaecologists. This survey and the follow ups could not have taken place without the considerable efforts made by midwives, health visitors, and members of the distric and area health authorities, and, of course, the mothers and

1 Ventura SJ. Trends and variations in first births to older women, 1970-1986. Vital and health statistics. Series 21(47). Hyattsville, MD: US Department of Health and Human Services, ville, 1989.

2 Kline J, Stein Z, Susser M. Conception to birth. Monographs in epidemiology and biostatistics. Volume 14. New York: in epidemiology and biostatistics.

3 Van Noord-Z Habbema JDF, de Velde ER, Karbaat J. Delayed childbearing: effect of age on fecundity and outcome of pregnancy. BMF 1991; 302:1361-5.

4 Berkowitz GS, Skovron ML, Lapinski RH, Berkowitz RL. Delayed childbearing and the outcome of pregnancy. $N$ Engl f Med 1990;322 (10): 659-64.

5 Cohen WR, Newman L, Friedman EA. Risk of labor abnormalities with advancing maternal age. Obstet Gynecol 1980;55: 414-16.

6 Grimes DA, Close GK. Pregnancy outcomes in black women aged 35 and older. Obstet Gynecol 1981;58 614-20.

7 Foreman MR, Meirik O, Berendes HW. Delayed childbearing in Sweden. $¥ A M A 1984 ; 252: 3135-39$. 
8 Wells-Nystrom BL, de Chateau P. Maternal age and transition to motherhood: Prenatal and perinatal assessments. Acta Psychiatr Scand 1987;76:719-25.

9 Harker L, Thorpe K. The last egg in the basket? Elderly primiparity - a review of findings. Birth 1992;19: 23-30.

10 Barkan SE, Bracken MB. Delayed childbearing: no evidence for increased risk of low birth weight and preterm delivery. Am f Epidemiol 1987;125(1):101-9.

11 Tuck SM, Yudkin SL, Turnbull AC. Pregnancy outcome in elderly primigravidae with and without a history of infertility. Br $\mathcal{F}$ Obstet Gynaecol 1988;95:230-7,

12 Cnattingius S, Foreman MR, Berendes HW, Isotalo L Delayed childbearing and risk of adverse perinatal outcome: A population-based study. $\mathcal{F A M A} 1992 ; 268(7)$ 886-90.

13 Aldous MB, Edmonson MB. Maternal age at first childbirth and risk of low birth weight and preterm delivery in Washington State. $\mathfrak{F A M A}$ 1993;270(21): 2574-7.

14 Roberts CL, Algert CS, March LM. Delayed childbearingAre there any risks? Med $\mathcal{f}$ Aust $1994 ; 160$ (9): 539-44.

15 Booth RT, Williams GL. Elderly primigravidae. 7 Obstet. Gynaecol Br Commonw 1964; 71:249-54
16 Frankel SA, Wise MJ. A view of delayed parenting: some implications of a new trend. Psychiatry 1982;45 (3):220-5.

17 Berryman JC, Windridge KC. Pregnancy after 35: a preliminary report on maternal-fetal attachment. fournal of Reproductive and Infant Psychology 1993;11:169-74

18 Ventura SJ. First births to older mothers. Am f Public Health 1989;79(12): 1675-77.

19 Chamberlain R, Chamberlain G, Howlett B, Claireaux A British births 1970. London: William Heineman, 1975

20 Weinberg WA, Dietz SG, Penick EC, McAlister WH. Intelligence, reading achievement, physical size and social class. A study of St Louis caucasian boys aged 8.0 to 9.6 years attending regular schools. $\mathcal{F}$ Pediatr 1985;4: 482-89.

21 Ounsted M, Moar VA, Scott A. Associations between size and development at four years among children who were small-for-dates and large-for-dates at birth. Early Human Development 1984;9(3): 259-68.

22 Brennan TL, Funk SG, Frothingham TE. Disproportionate intra-uterine head growth and developmental outcome. Dev Med Child Neurol 1985; 27(6): 746-50.

23 Rutter M, Tizard J, Whitmore K. Education, health and behaviour. London: Longman, 1970. 